\title{
Maxillofacial radiology case 163
}

\author{
SADJ August 2018, Vol 73 no 7 p459
}

CJ Nortje

Below are cases of reactive lesions from various patients presenting at the department. What are the most important radiological features and what is your diagnosis?

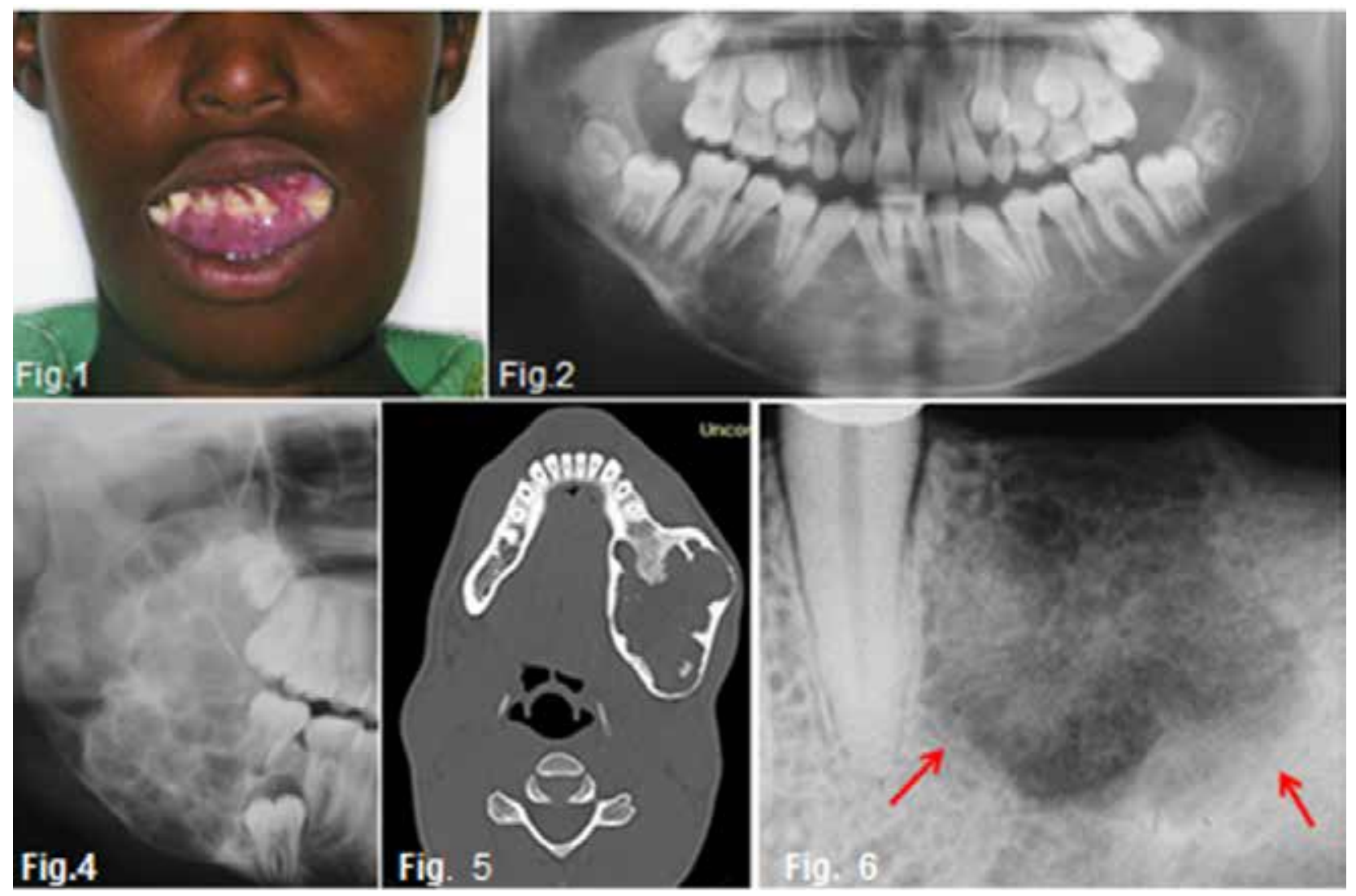

INTERPRETATION

Figure1\&2 shows an aggressive lesion in a 14 year old male patient. The pantomograph show the lesion extending from the 36 to the 46. Expansion of the cortex and divergence of the roots is discernible. A histological diagnosis of a Central giant cell granuloma (CGCG) of the bone was made. The original term of CGCG was coined by Jaffe in 1953, when he suggested that this lesion should be distinguished from the Central giant cell tumour (GCT) of bone. Jaffe believed that the CGCG is a reactive lesion, whereas the CGT is a neoplasm. Central giant cell granuloma of the jaws is considered to be a fairly common benign reactive lesion. It is characterized by the presence of numerous multinucleated giant cells. The CGCG most commonly affects young people and over $50 \%$ of cases occur in the first two decades of life. The average age of occurrence is 21 years, with a range of 3 to 68 years. Females are affected slightly more than males. The mandible is affected in the majority of cases, with the anterior segments being affected more often than the posterior. Radiographically the lesion is essentially radiolucent, often with a multilocular, soap bubble appearance (Fig.3). A rather marked expansion with thinning of the cortical plates is a characteristic finding (Fig.4). The tumour usually destroys the lamina dura and causes displacement of the teeth (Figs.2\&3). It may lie in

CJ Nortjé: BChD, PhD, $A B O M R$, DSc. Faculty of Dentistry, University of the Western Cape. E-mail: cnortje@uwc.ac.za intimate contact with the teeth, causing very few changes; in other areas it may cause extensive root resorption. This root resorption is usually irregular and leaves a ragged surface in contrast to the smooth resorption seen in association with cysts. According to Langlais et al.(1994), CGCG's can present with an aggressive or non-aggressive behaviour. The basis for this division consisted of histologic, clinical and radiological factors. The radiological features of the aggressive type include resorption of adjacent root apices, perforation of the expanded cortex and a diameter exceeding $2 \mathrm{~cm}$; nonaggressive lesions are characterized by the absence of root resorption, intact cortices and a diameter smaller than $2 \mathrm{~cm}$. A peripheral variant of this lesion occurs in the gingiva and produces an epulis-like soft tissue mass in the gingival region. In a edentulous area it may result in a nodule or swelling on the alveolar ridge and may present radiologically with a typical "peripheral cuffing" (red arrows, Fig.5). The CGCG are known to recur, and recurrence is a feature of the aggressive type and may require curettage plus peripheral ostectomy A histological diagnosis of CGCG must always be followed by a workup for the possibility of the presence of a "Brown" tumour of hyperparathyroidism.

\section{References}

1. Jaffe HL: Giant cell reparative granuloma, traumatic bone cyst and fibrous (fibro-osseous) dysplasia of the jaw bones. Oral Surg Oral Med Oral Pathol 6: 1953, p159.

2. Langlais RP, Langland OE \& and Nortje CJ: Diagnostic Imaging of the Jaws, Williams and Wilkins. 1995, p 351-6. 